\title{
The Joint Audit in Bulgaria - Issues and Prospects
}

\section{Snejana Bacheva*, Daniela Petrova*, lavor Bachev" ${ }^{\text {t** }}$}

\begin{abstract}
This piece of research is the first one conducted in regards to the applicability of the joint audit in Bulgaria. The paper summarizes the stakeholder environment in regards to the joint audit in The Republic of Bulgaria after the new Independent Financial Audit Act (IFAA) was adopted and performed for the first time in the country.This aim is achieved by using a survey sent to three groups of potential respondents that are also stakeholders in the whole process. The first group is the group of auditors, the second are supervisory institutions and the third are the entities whose financial statements are subject to joint independent financial audit. The paper ends with an outline of the positive aspects and difficulties in joint audits in the Bulgarian context as well as the recommendations made by the respondents for improving the overall process.
\end{abstract}

Keywords: audit, joint audit, accounting legislation

JEL: M40, M42, M48

\section{Introduction}

In November 2016, a new Independent Financial Audit Act (IFAA) was adopted in the Republic of Bulgaria which transposed the requirements of Directive 2006/43/EC, amended by Directive $2014 / 56 / E U$, as well as of Regulation (EU) 537/2014. The Act contains significant changes, particularly, in respect of the audit of public-interest entities (PIE), as well as in respect of the obligations of audit committees. The Act introduces a number of new basic principles, such as a mandatory rotation of registered auditors, a prohibition on the provision of certain services, restrictions to the fees for non-audit services, and the use of joint audit. A joint audit is carried out by two audit firms and is required for insurers, reinsurers, pension companies and credit institutions. These companies appoint their auditors after having agreed in advance on the appointment with the relevant regulators, i.e. the Financial Supervision Commission (FSC) or the Bulgarian National Bank (BNB). The criteria for agreeing the appointment of auditors are approved by the relevant regulator (FSC or BNB), in consultation with the Commission for Public Oversight of Registered Auditors (CPOSA). The article summarizes the outcome of the survey carried out regarding the implementation of

\footnotetext{
${ }^{1}$ University of National and World Economy, Department: Accountancy and Analysis

${ }^{2}$ University of National and World Economy, Department: Financial Control

${ }^{3}$ University of National and World Economy, Department: Financial Control
} 


\section{Articles}

joint audit in Bulgaria in the first year after the introduction of the mandatory joint audit.

\section{Presentation}

In the survey, the selection of respondents is based on a fundamental element for the purposes of this study, i.e. the relevance of joint audit in auditing the financial statements in Bulgaria. Respondents come from public institutions, companies subject to statutory joint audit and audit firms. The study ensures the adequate comparability among respondents. All of them are experienced in the field of joint audits and have dealt with diverse circumstances. The respondents have been motivated by reminding them of the importance of the study and the benefits which it could provide to their work, shedding light on the issues related to joint audits in Bulgaria. The respondents have been allocated to three groups: the first group comprises supervisory institutions; the second group comprises audit firms which have carried out joint audits, and the third group comprises entities whose annual financial statements are subject to a joint financial audit. The researchers have contacted all respondents via email, phone, in person or using the connections of professional bodies, for example, universities and organizations, such as, the Institute of Certified Public Accountants, the FSC, etc.

Of the 103 questionnaires distributed (two questionnaires in the first group; 25 questionnaires in the second group and 76 questionnaires in the third group of respondents), a total of 47 responses have been received, including two responses in the first group; 18 responses in the second group and 27 responses in the third group.

The researchers believe that the semistructured questionnaire is the best way to achieve the objectives of the study. According to Lincoln and Guba (1989), it is important for the participants to be able to understand the concepts, conceptions and topics of the scientific research. Accordingly, the questionnaires have been sent to individuals possessing the required knowledge and experience who were in a position to cast light on the topics under research. The questionnaires have been developed using Google forms and have been disseminated in electronic format via a link that guides the user to the online form. The questions are in the Bulgarian language. Besides, following the recommendations of Bryman and Bell (2003), it is advisable for the questionnaires to be answered "in relaxed environment" where the risks of interference and/or distraction of attention are reduced to a minimum. The expected time to answer the questionnaires is about 30 minutes, depending on the survey. The venue and timing for completing the questionnaire is a matter of personal choice of each respondent. All respondents have been provided with a term of at least few weeks to complete the questionnaire, before terminating receipt of replies in relation to the study. In case a respondent had certain concerns or queries, the researcher has indicated his or her e-mail and phone number and has accordingly been at the disposal of the respondent. A non-random sample has been used, insofar as the sampling units have been deliberately selected and not at random, as no statistical representativeness is required and specific features of the units are being sought (Ritchie, 2003). The main criterion has been knowledge and experience in relation to the relevant topics. Nevertheless, a wide range of various experts have been contacted to cover as many institutional aspects of the industry as possible. Although a non-random sample was used, the number of collected responses, i.e., 47 is representative as a percentage of the total number of experts in the relevant field. No theoretical sampling has been used, i.e., no additional individuals for interviewing and other sources of data have been selected in the course of the study where provisional concepts have been designed and the need for additional questions has been identified 


\section{Articles}

(Boeije, 2002). The reason for this is that in order to ensure comparability between the answers to the questions, the questionnaire must be one and the same for all participants in the study.

Three types of questionnaires have been developed for the three groups of respondents. The first questionnaire was intended for the supervisory institutions in the Republic of Bulgaria, i.e. the Banking Supervision and the FSC. The second questionnaire was intended for auditors who have carried out joint audits. The third questionnaire was intended for entities whose financial statements are subject to joint audit, such as, pension companies, insurance undertakings, banks.

The questionnaires have been structured by the researchers in accordance with each topic of interest. As already mentioned, the questionnaires forwarded to the potential groups of respondents are identical, to ensure comparability and facilitate the aggregation of findings. Each question represents a notion, avoiding unnecessary professional jargon and abbreviations. All questions whose representation contains a hint to a certain response have been avoided, save for a question based on specific theoretical frameworks. The questionnaire contains both open-ended and closed-ended questions.

The ten questions in each questionnaire may be summarized in a few categories on the basis of a common denominator with regard to the relevant aspects of the study. The questions are clearly stated so there is no need for additional clarification and are based on the relevant theories and concepts as discussed in the literature references.

\section{Data Coding and Analysis}

Data from the questionnaire
(questionnaires) have been collected after
the access thereto has been terminated.
Data have been encoded and categorized by
topic on the basis of each topic of interest
for the study, to achieve the objective of

managing, organizing and focusing on the most meaningful parts of the qualitative data (Malhotra and Birks, 2007). The encoding process proposed by Lofland et al. (2006) has been used to organize collected data in different categories and topics, derived from the relevant literature, which then become the basis for the aggregation. The main focus is on the continuous comparison between theory and data (Boeije, 2002), to ensure adequate comparability of the findings and conclusions of the study. The structure of the questionnaire has been designed in such a way as to make a clear distinction and smooth transition between the various topics. The responses to the questionnaire have been initially processed using the software provided by the Google forms, after which they have been exported to Excel where additional processing has been performed.

\section{Ethical Considerations}

The considerations regarding the qualitative nature of the research have been addressed through the voluntary participation and the informed consent together with the protection of identity and confidentiality (Vaus, 1996). All participants have been informed about the objective and the benefits of the study, providing then with a deadline within which they could withdraw their response. The general issues of participants' anonymity and personal data protection (Gray, 2009), as well as data protection and collection, have been neutralized and thus the questionnaire has become fully anonymous, i.e. only the date of completing the questionnaire and the respondent's replies have been kept. There is no mention of any institutions or cases. Accordingly, no information can be linked to a particular person or company. All participants have expressed their consent to participate, provided they remain anonymous, with no possibility to track a link to the company for 


\section{Articles}

which they work. Permission to use the data for this study has been given with each person accepting to complete the questionnaire.

\section{Data Credibility and Authenticity}

In conducting qualitative research, the concepts of credibility and authenticity are of extreme importance (Bryman and Bell, 2003). Credibility: with regard to data, we are satisfied that credibility has been achieved by ensuring their transferability, reliability and verifiability. There is a distinction between transferability in quantitative and qualitative research. In the first case, it is wider in nature and the findings can easily be expressed in general terms, while in the latter case, it would be more detailed and more narrowly focused (Bryman and Bell, 2003). The researchers believe that the number of responses received is sufficient to provide a more complete picture of the matters covered. Reliability is achieved through full transparency in the research process and the steps undertaken. In addition, it is reinforced by the explanation of the study at the beginning of the questionnaire and the topics covered thereby. Data verifiability in qualitative research, it is not possible to achieve full objectivity (Bryman and Bell, 2003). We guarantee that the entire study has been conducted in the most unbiased and objective way possible. Authenticity: whether a researcher presents adequately the information gathered using the questionnaire. To ensure that this is the case, we were satisfied that in the analysis of data there has been no misunderstanding with regard to contentious matters, as well as that the data have been summarized and summed up correctly.

\section{Results and Summaries}

The first group of respondents comprises the two supervisory institutions in the Republic of Bulgaria, i.e., the Banking Supervision and the FSC. Of the two questionnaires sent to this group in the period of collecting the responses, two responses were received, whereby the percentage of responses equalled $100 \%$.

The second group of respondents comprises audit firms which carried out joint audits in 2017. Of the 25 questionnaires sent out to this group in the period of collecting the responses, 18 responses were received, whereby the percentage of responses equalled $72 \%$, an acceptable percentage, given the nature of the study and the time needed to reply to all questions included.

The respondents come from various types of audit firms, including firms from the "Big Four", other international audit network firms, local audit firms with no foreign capital participation in the ownership structure. Of those that have provided a response, local companies with no foreign capital participation

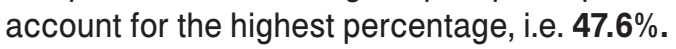
Of the "Big Four", a response has only been received from one audit firm. Of those that have provided a response, $\mathbf{3 8 . 1} \%$ have carried out more than seven joint audits of financial statements, while $\mathbf{2 6 . 7 \%}$ - between one and three joint audits.

The third group of respondents comprises companies whose financial statements were subject to a joint audit in 2017. Of the 76 questionnaires sent out to this group, in the period of collecting the responses, 27 responses were received, whereby the percentage of responses equalled $36.0 \%$ ( $49 \%$ of non-banking institutions), the nonbanking financial institutions which have provided a response include insurance, reinsurance and pension companies. Of those providing a response, $\mathbf{7 4 . 1 \%}$ are insurance and reinsurance undertakings and $25.9 \%$ pension companies.

\section{Results from the Survey of the First Group of Respondents - Supervisory Institutions}

The analysis of the results should take account of the fact that only two supervisory institutions have been surveyed (the Banking 


\section{Articles}

Supervision Department with the BNB and the FSC), as only they are relevant to joint audits, insofar as the joint audit has been introduced as mandatory in respect of the commercial banks, the pension companies and the funds managed thereby, and the insurance undertakings.

Some $100 \%$ of the respondents believe that audit service market concentration is a major issue leading to a systemic risk. Half of those that have provided a response believe that the way to overcome these negative consequences of market concentration is the implementation of a statutory joint audit, indicating also other ways for dealing with the problem. One of the solutions suggested by respondents for overcoming the negative consequences of market concentration is for BNB as a supervisory authority to implement additional criteria in respect of both the audit firms and the responsible auditor.

The implementation of statutory joint audit as a solution to market concentration?

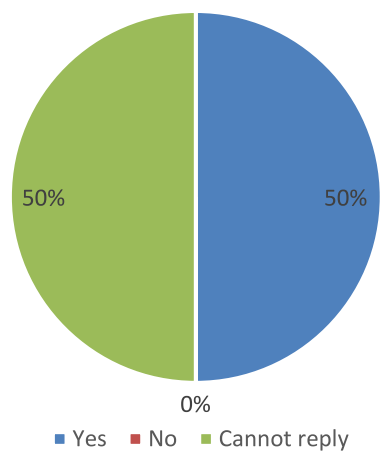

Figure 1.

In respect of enhancing the quality of financial statements after the introduction of joint audits, $50 \%$ of the respondents are of the opinion that the quality of the financial statements, respectively of the information contained therein, has increased. The rest have indicated that they cannot provide a reply. In the context of the difficulties in measuring the quality of audit, this is an expected result.
Has the quality of the financial statements increased after the introduction of the joint audit?

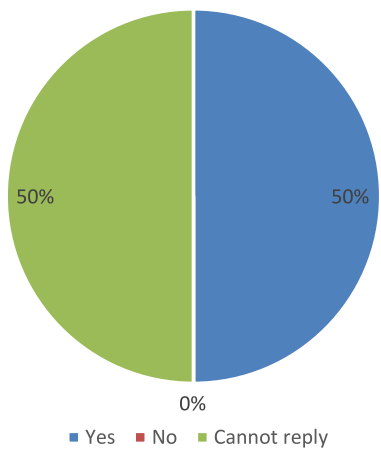

Figure 2.

None of the respondents have had any difficulties in communicating with the auditors after the introduction of the statutory joint audit.

To the question regarding which of the joint audits performed for the year ended 31 December 2017 had the highest effectiveness, the respondents could not provide a precise answer (Figure 3). The answer to this question suggests the lack of analysis of the expected impact from the introduction of the joint audit which could be explained by the short period of time after the implementation of the statutory joint audit in Bulgaria.

In your opinion, of the joint audits performed for the year ended 31.12.2017, the highest effectiveness have those carried out by:

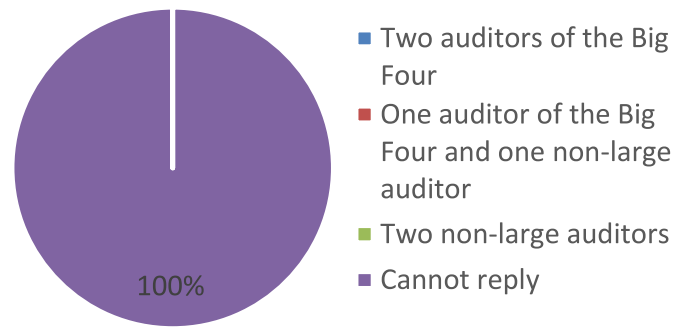

Figure 3.

According to the respondents from the supervisory institutions, the positive aspects of the newly introduced statutory joint audit include: providing the opportunity to a larger number of registered auditors to enter the 


\section{Articles}

market, reducing the dominance of Big Four audit firms (100\%); reducing the potential for purchasing an opinion (50\%) and allowing for technology transfer and helping to promote good practices in the external audit.

On the basis of last year's experience, the negative aspects according to the respondents include: increasing the cost of audit, difficulties in the division of work between the two auditors, and difficulties in reconciliation of the different methodologies used by the two auditors. One of the respondents has given a recommendation regarding this latter negative aspect, specifically noting that the process of unification of the methodologies applied by the audit firms should be improved and so should the division of audit work in order to cover to a significant extent the various reporting items.

On the basis of the experience in the first year, $100 \%$ of the respondents cannot provide a reply as to whether a need has been identified for amendments to the effective Independent Financial Audit Act and the Guidelines of CPOSA and ICPA for Performing Joint Audits. One of the respondents has noted the fact that, as of now, there is in practice only one financial year in this respect, which is in itself an insufficient period to provide an effective response to this question.

To summarize, for the supervisory institutions in the Republic of Bulgaria, the period of one year is insufficient to provide an objective opinion as to the effectiveness of joint audits in improving the quality of the financial information presented in the financial statements, as well as to the need for amendments to the effective Independent Financial Audit Act and the Guidelines of CPOSA and ICPA for Performing Joint Audits. Nevertheless, the respondents have defined positive and negative aspects of the implementation of joint audits.

\section{Results from the Survey of the Second Group of Respondents - Auditors}

The respondents to this survey include representatives of both local audit firms and international audit network firms (Big Four excluded, with a total percentage of $76 \%$ of those that have provided a response). Only one Big Four firm took part in the survey.

The number of joint audits carried out by the respondents varies, with $38 \%$ of those that have provided a response specifying that they have taken part in more than 7 joint audits.

The most common positive aspects of joint audits specified by respondents include: increasing audit quality (62\%); providing the opportunity to a larger number of registered auditors to enter the market, reducing the dominance of Big Four audit firms; allowing for technology transfer and helping to promote good audit practices.

The respondents consider as negative aspects of the joint audit (specified by more than $40 \%$ of the respondents): difficulties in communication; increasing the cost of audit, difficulties in reconciling the different methodologies used by the two auditors and the possibility that some aspects of the audit work would be duplicated while others would be omitted.

In near $62 \%$ of the cases, the respondents believe that one of the two registered auditors performing the joint audit should have a leading role in respect of coordination.

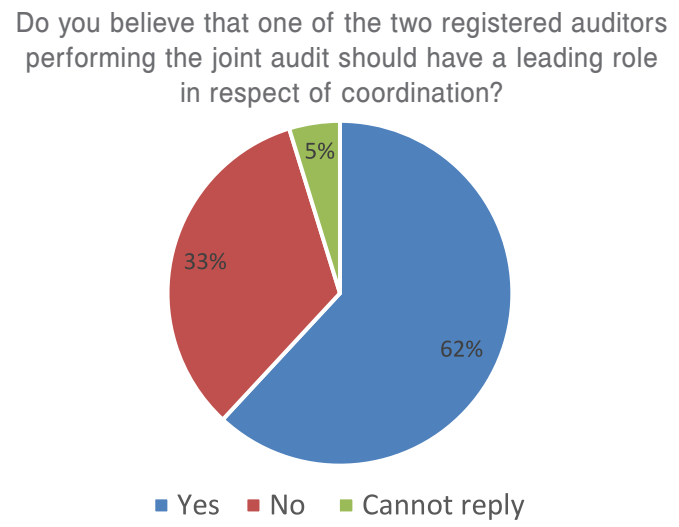

Figure 4.

To the question regarding whether one of the two registered auditors performing the joint audit should take greater responsibility 


\section{Articles}

for which this auditor should also get higher remuneration, $57 \%$ of the respondents believe that this should not be the case, while $29 \%$ give a positive reply.

Do you believe that one of the two registered auditors performing the joint audit should take greater responsibility for which this auditor should also get higher remuneration?

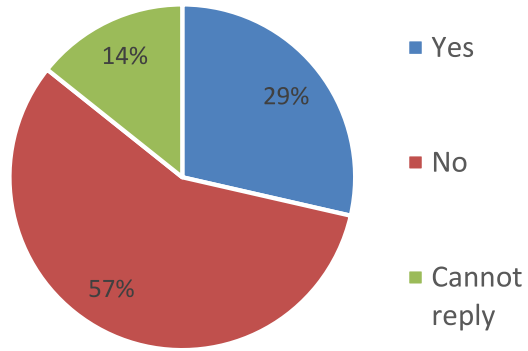

Figure 5.

Of course, the reply of respondents may have been influenced by the fact that professional indemnity insurance has different limits and there is a difference in auditors' ability to deal with possible litigation claims in relation to the audits performed and the reports issued. Thus, in practice it may turn out that one of the auditors would have greater responsibility from that perspective. In relation to this issue, one of the respondents noted that if one of the auditors has been designated as a leading auditor, as is the case now, including also in respect of his or her remuneration, which in most cases would be multiples of the remuneration of the other auditor, it would not be appropriate for the second auditor to be held jointly and a liable together with the first auditor.

All respondents replied that audit procedures had been performed separately on the basis of the agreed upon division of work. Some of the respondents indicated that in case of significant lack of resources, experts and practices in the industry, duplication of work may arise as a result. Some of the respondents provide as an example the case where, after performing the agreed upon procedures and reviewing the work carried out, one of the two auditors has performed additional procedures to obtain "sufficient appropriate" evidence.

Only $14.3 \%$ of the respondents believe that, on the basis of the experience in the first year, a need has been identified for amendments to the effective Independent Financial Audit Act and the Guidelines of CPOSA and ICPA for Performing Joint Audits:

Do you believe that, on the basis of the experience in the first year, a need has been identified for amendments to the effective Independent Financial Audit Act and the Guidelines of CPOSA and ICPA for Performing Joint Audits?

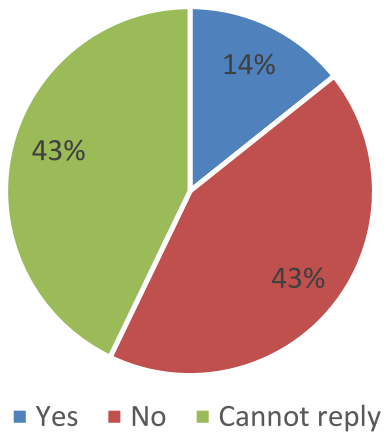

Figure 6.

The recommendations concern amendments to the Guidelines for Performing Joint Audits and include recommendations such as that the Guidelines should be more closely aligned with practice and that the requirements relating to the mutual review of the joint work should be set out in more detail.

Part of the respondents believed that there are also other ways to improve audit quality, such as the use of other mechanisms for control of the audits performed (an audit committee, reviews by CPOSA, internal quality control systems and procedures).

To the question regarding what could be improved in a joint audit, the respondents have specified a few main points:

- Communication; 


\section{Articles}

- Timely planning and coordination of the audit process;

- Developing guidelines for the division of work, without a possibility for duplication of the procedures performed;

- Specifying in more detail the opportunity for each auditor to take part in joint audits on the basis of expertise in the relevant industry;

- The attitude of clients (users of this service).

As of now, some of the respondents believe that a view is artificially imposed that joint audits constitute counterproductive labour and a useless increase of costs for clients.

\section{Results from the Survey of the Third Group of Respondents - Entities Whose Financial Statements Are Subject to Joint Independent Financial Audit}

On the basis of respondents' replies, the four most commonly indicated characteristics forming the content of a joint audit include:

a) the procedures related to engagement acceptance are carried out jointly (81.5\%);

b) joint issuance of an audit report on the audited financial statements (77.8\%);

c) joint and several responsibility for the audit opinion expressed (70.4\%); and

d) to obtain evidence, each of the two auditors performs the procedures provided for in ISAs (International Standards on Auditing) (59.3\%).

The lowest number of replies by the respondents refers to: the procedures related to client and engagement acceptance are performed separately by each of the two auditors (7.4\%) and the existence of individual
The Joint Audit in Bulgaria - Issues and Prospects

liability of each of the two auditors (11.1\%). These answers have been included in the question in order to examine whether the respondents are aware of the essential features of a joint audit. The insignificant number of respondents who have indicated those features as determining the nature of a joint audit confirms the hypothesis that despite the short period of operation, joint auditing is a concept which is correctly understood and well known.

With regard to the positive aspects of a joint audit, the respondents have provided the following most common answers:

- No positive aspects (37\%);

- Improving audit quality (37\%);

- Allowing for a transfer of technology and helping the promotion of good practices (33.3\%);

- Improving investor confidence (33.3\%).

In one of the cases the respondent has provided comments, specifying that a joint audit is "an unprecedented practice established in Bulgaria. Joints audits are being carried out solely in France and only in respect of the consolidated financial statements".

It is worth noting the relatively high percentage of those who have indicated that a joint audit has no positive aspects at all, which is rather an indication of prejudice or bias.

On the other hand, the most commonly stated by the respondents negative aspects of a joint audit include: leads to an increase in the costs for audit (85.2\%), greater client involvement $(74.1 \%)$, and difficulties in communication (44.4\%).

Some of the respondents have also indicated "...lack of past year experience, in accordance with Art.101 and Art 16 of the Insurance Code...", as well as "...failure to

\footnotetext{
${ }^{1}$ In the analysis, this answer has not been taken into consideration, as clearly in this case the respondent has not taken into account the fact that the appointment of an auditor is coordinated in advance with the FSC and the criteria of the Commission include first of all the requirement for experience in the field of the relevant industry.
} 


\section{Articles}

comply with the term for submitting the report by the audit firm...".

In respect of the division of work between the two auditors, $73.1 \%$ of the respondents believe that the auditors conducting a joint audit have performed audit procedures separately on the basis of the agreed division of work. Nevertheless, a little bit more than $1 / 4$ of those who have provided a response indicate that each auditor has performed the audit procedures considered necessary thereby. If audited entities have the perception that procedures are being duplicated and the work is not divided to a sufficient extent, this may also indicate a possible reason for the higher audit fees.

How did the two auditors conducting the joiny audit divide the work?

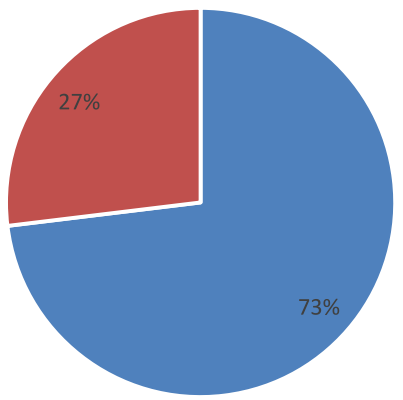

- They performed the audit procedures separately on the basis of the agreed division of work

- Each auditor performed audit procedures as considered necessary thereby

Figure 7.

In respect of the increase in costs after the introduction of joint audits, as compared with $2016,92.6 \%$ of the respondents have replied positively. The most common percentage increase is around $50 \%$, but there is a high variation in responses, even reaching $120 \%$. The responses to this question should be compared with the additional analysis regarding the increase in the costs for audit performed on the basis of the financial statements published.
More than $50 \%$ of the respondents cannot assess whether the quality of the financial statements for the year ended 31 December 2017 has improved as a result of the joint audit. Nevertheless, $22 \%$ are explicit that as a result of the joint audit financial statement quality has improved. An analogy can be made with the responses of the supervisory institutions.

In your opinion, has the quality of the financial statements for the year ended 31.12.2017 improved as a result of the joint audit performed?

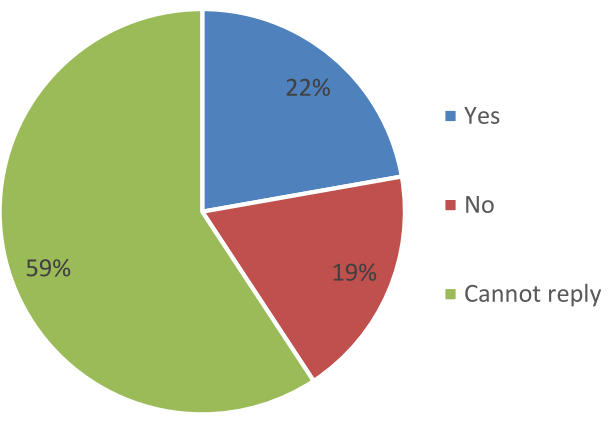

Figure 8.

$70.4 \%$ of the respondents are of the opinion that in a joint audit the number of the matters covered is not higher than in an audit performed by a single auditor.

In your opinion, does a joint audit cover higher number of matters than an audit performed by a single registered auditor?

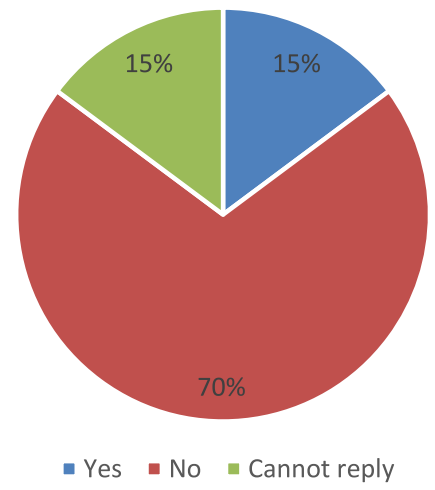

Figure 9.

Even higher is the percentage of those who have responded that they do not believe 


\section{Articles}

that the benefits of a joint audit outweigh the costs $(77.8 \%)$. This percentage is indicative of the overall attitude towards the joint audit.

Do you believe that overall the benefits of a joint audit outweigh the costs?

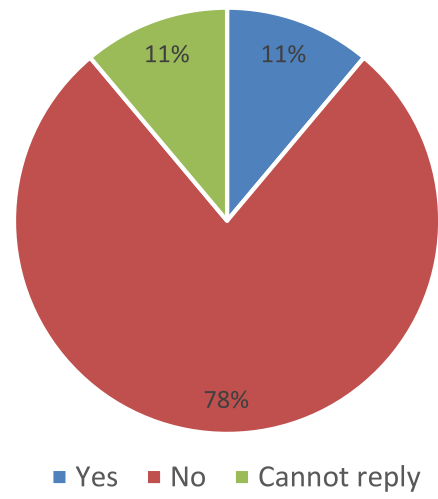

Figure 10.

The additional comments provided to the question "What, in your opinion, could be improved in a joint financial audit?" indicate that, overall, the respondents to this survey have most often raised the question about the removal of the joint audit (25\% of comments). This result, compared with the answer to the previous question, suggests however that, despite the predominant opinion that the benefits do not outweigh the costs, only $25 \%$ are of the opinion that the joint audit should be removed. None of the respondents suggests replacement of the statutory joint audit with a voluntary one which might be due to both unawareness of the existence of such a possibility and the perception that the first year of the implementation of a new requirement is not a sufficient period for such definite judgements. One of the respondents has expressed the view that "...such an audit would only make sense for the consolidated financial statements and not for companies' separate or individual accounts...".

Other comments provided by respondents include:
The Joint Audit in Bulgaria - Issues and Prospects

- Standardization of the schedules and procedures for the audit;

- Linking the fee to the volume of work at the relevant insurer/company;

- To be replaced with an audit by a single audit firm, requiring an adequate team, in line, as number of persons and competence, with the size of the audited company;

- Preliminary and timely coordination of the work, on the one hand, between the auditors themselves, and on the other hand, between the auditors and the client;

- A single audit methodology by type of entities;

- Remote regulated access of auditors to the financial and accounting software and the software for record-keeping of documents, contracts, a;

- Division of work between the auditors and time limits for the performance of each task;

- Precise organization of the work of audit teams and the client in order to avoid duplication of activities;

- Very good team work, interaction and unification of the procedures of auditing firms.

Most of the comments can be summarized in three areas, i.e., related to the financial price of audit, the improvement in work efforts and the communication between the auditors and the client.

Outside the survey, in an interview made with representatives of the supervisory institutions, the question has been raised as to what should be the response of information users, in particular, the supervisory institutions, where the two auditors participating in the joint audit have expressed a different opinion. From the view point of supervision, this possibility, albeit not 


\section{Articles}

having been materialized in the period under review, constitutes a material deficiency of the joint audit. It is worth noting here that such concerns are rather hypothetical in nature insofar as the Guidelines for Performing Joint Audits, adopted in June 2017 by CPOSA and ICPA, specify that the two auditors should determine common materiality and threshold for uncorrected misstatements for the entire engagement.

In case of disagreement arising from the different methodologies applied by the auditors, in accordance with the conservative approach, the lowest relevant materiality should be used. This approach restricts to a minimum the possibility for divergence of opinion. In view of the impossibility of expressing absolute assurance and the application of the principle of prudence, a possible solution in such circumstances would be the acceptance of the more restrictive opinion with an additional paragraph explaining the differences in opinion.

\section{Conclusion}

The various respondents in the survey (auditors, audited entities and supervisory institutions) provide different perspectives to joint audits.

The three parties highlight both positive and negative aspects of joint audits. As a whole, the following positives and negatives (difficulties) predominate:

\begin{tabular}{|l|l|}
\hline Positive aspects & Difficulties in a joint audit \\
\hline $\begin{array}{l}\text { Improves the quality of } \\
\text { audits }\end{array}$ & $\begin{array}{l}\text { Difficulties related to the } \\
\text { different methodologies applied }\end{array}$ \\
\hline $\begin{array}{l}\text { Provides the opportuni- } \\
\text { ty for a higher number } \\
\text { of registered auditors } \\
\text { to enter the market }\end{array}$ & Increases the costs for audit \\
\hline $\begin{array}{l}\text { Technology transfer } \\
\text { wifficulties in the division of } \\
\text { work between the two auditors }\end{array}$ \\
\hline & $\begin{array}{l}\text { Problems with communications } \\
\text { and planning }\end{array}$ \\
\hline
\end{tabular}

As could be expected, the direct link between the joint audit and enhancing audit quality predominates among audit firms, while with regard to the audited entities, only $37 \%$ of the surveyed entities found such a link to exist.

Less than half of the surveyed auditors indicate that an advantage of a joint audit is "that it provides the opportunity to a larger number of registered auditors to enter the market, reducing the dominance of the Big Four audit firms". A conclusion can be drawn, that for local audit firms, audit service market concentration is not such a significant issue. Nevertheless, this matter should be considered taking also into account the results of other studies, besides this survey.

The recommendations made by respondents can be summarized as follows:

\begin{tabular}{|l|l|}
\hline Recommendations & \\
\hline $\begin{array}{l}\text { Focus on other mechanisms } \\
\text { for quality control on the } \\
\text { audits performed (an audit } \\
\text { committee, reviews by } \\
\text { CPOSA, internal quality } \\
\text { control systems and } \\
\text { procedures). }\end{array}$ & $\begin{array}{l}\text { Unification of the } \\
\text { methodologies applied } \\
\text { in the audit. }\end{array}$ \\
\hline $\begin{array}{l}\text { Auditor specialization in a } \\
\text { joint audit. }\end{array}$ & $\begin{array}{l}\text { An emphasis on the } \\
\text { benefits of join audits. }\end{array}$ \\
\hline $\begin{array}{l}\text { Better coordination between } \\
\text { the two auditors in a joint } \\
\text { audit to reduce client } \\
\text { involvement. }\end{array}$ & $\begin{array}{l}\text { Looking for an } \\
\text { opportunity to reduce } \\
\text { the financial burden of a } \\
\text { joint audit. }\end{array}$ \\
\hline
\end{tabular}

As in any research, a reasonable skepticism should be exercised in respect of respondents' assessments and recommendations which appear superficial. Summarizing the recommendations made, it may be stated that the expectations (of both audited and auditing entities) tend to focus on improving the organization of joint audits, so that some of the deficiencies highlighted could be overcome. To facilitate this process, CPOSA could, in subsequent quality assurance reviews, pay attention as to how the work has been planned and divided 


\section{Articles}

between the joint auditors, whether the requirement for balanced split (up to 60/40 percent of total volume) has been complied with, and whether the memorandum drawn up on the division of audit procedures has been adequately implemented. This would mean that both audit firms which have carried out the joint audit should be simultaneously included in the quality assurance review plan, contemplating also review questions covering the specifics of joint audit.

The proposal to seek opportunities to reduce the financial burden of joint audits cannot be implemented by administrative means. Nevertheless, it is worth considering whether some of the anomalies in audit service pricing arise from the inappropriate understanding or the incorrect application of joint audit requirements.

\section{References:}

Guba, E., and Lincoln, Y.Fourth generation evaluation. Newbury Park: SAGE,1989

Ritchie, J. Qualitative Research Practice: A Guide for Social Science Students and Researchers.London: Sage Publications, 2003.

Boeije, H. A Purposeful Approach to the Constant Comparative Method in the
The Joint Audit in Bulgaria - Issues and Prospects

Analysis of Qualitative Interviews'. Quality and Quantity. Vol. 36, 2002, 391-409.

Malhotra, N., and Birks, D. Marketing Research. An Applied Approach, 3rd edition,Essex: Pearson Education Limited, 2007.

Lofland, J., Snow, D., Anderson, L., and Lofland, L. Analyzing Social Settings: A Guide to Qualitative Observation and Analysis, 4th Edition, London: Wadsworth, 2006.

Vaus, D. Surveys in social research. 4th ed. London: UCL Press Limited. 1996

Gray, D. Doing Research in the Real World. 2nd ed. Sage Publications Ltd, 2009

Bryman, A. and Bell, E. Business research methods. Oxford. Oxford University Press, 2003.

European Commission. (2010) Green Paper - Audit Policy:Lessons from theCrisis,Brussels,13.10.2010.(http:// ec.europa.eu/internal_market/consultations/ docs/2010/audit/green_paper_audit_en.pdf EC (2011b) Summary of responses Green Paper - audit policy: Lessons from the crisis, 4th February 2011, European Commission, Brussels, pp. 1-36 